\title{
APPLICATION OF THE CHIMNEY CAP AS A METHOD OF IMPROVING THE EFFECTIVENESS OF NATURAL VENTILATION IN BUILDINGS
}

\author{
Romana Antczak-Jarząbska \\ Maciej Niedostatkiewicz \\ Gdańsk University of Technology, Poland
}

\begin{abstract}
Adequately designed natural ventilation is the cheapest and easiest way to effectively remove indoor pollutants and keep the air inside a building fresh. A prediction of the performance and effectiveness of ventilation in order to determine the design of a ventilation system can provide real and long-term cost savings. The worst time in terms of the efficiency of natural ventilation is the spring-autumn transition period [7]. In order to improve the efficiency of natural ventilation, chimney caps are used, among others. They are designed to improve the chimney effect described in colloquial language as a chimney draft. The chimney effect is a physical phenomenon of the formation of a spontaneous flow of a warmer gas, e.g. air, from the bottom up in stem channels [12]. The article analyses the influence of the chimney cowl on the improvement of the chimney effect in an apartment of a multi-family building with natural ventilation. Long-term tests of the chimney draft were carried out for the case without and with a chimney cap. The paper presents the results of the performance (air change rate, ACH) of natural ventilation for a building with an inlet gap measured for the transitional season (between the heating and the summer season). The measurements were performed during a windy period.
\end{abstract}

Keywords: natural ventilation,chimney cap,ACH,wind effect,effectiveness

\section{INTRODUCTION}

Natural ventilation (NV) is the cheapest strategy for distributing fresh air inside a building. It is still the most popular system found in Poland and other Central and Eastern European countries. Natural ventilation is driven by two physical phenomena, wind $[9,11]$ and buoyancy (stack effect) caused by the difference between the indoor and outdoor air temperatures $[9,11]$.

However, Gładyszewska et al. [8] showed that NV is mainly affected by the wind direction and velocity. Natural ventilation should work when all or one of the natural forces are available. Unfortunately, the two main drivers causing natural ventilation flows are stochastic, so natural ventilation may be difficult to control and difficult also to predict, analyse and design. Other disadvantages of natural ventilation are the reduced control of air distribution within the building and its ineffectiveness in summer conditions with minimal wind. Despite the difficulty in control, natural ventilation is still relied upon to meet the need for fresh air in many buildings. The study[10] shows that natural ventilation has become a new trend in building design in the architectural community. Furthermore, natural ventilation has been used in many types of buildings, even in hospitals with highly controlled indoor climates [6].

The quality of natural ventilation is usually determined by the performance indicator of the ventilation system. Performance means the air change rate $(\mathrm{ACH})$. The $\mathrm{ACH}$ 
measures how quickly the air in the interior space is replaced by air coming from the outside. In turn, ventilation effectiveness is the indicator of the ability of a ventilation system to remove a contaminant. Ventilation performance indicators serve to provide information concerning indoor air parameters in a room or a building. Therefore, proper information about the actual climate data of the local climate conditions is important, but is usually not provided. Generally, we have two different approaches: the local climate condition (LCS) at the construction site and climate data in atypical meteorological year (TMY). In engineering practice, it is not common to take into account the local climate conditions. As we can see in [13], the most common practice is to use climate data from the TMY. However, [13] rightly observed that when based on climate data from the TMY, such values are usually slightly over estimated. Therefore, in-situ measurements were used in the tests.

In this paper, the performance (air change rate, $\mathrm{ACH}$ ) of natural ventilation for a building with a measured inlet gap was performed. A typical residential detached house, located in northern Poland, in a cold climate region, was chosen for the measurement campaign. Field measurements were performed in a test apartment in a detached family house. The measurement campaign ran from 2 April to 9 June. For better knowledge of the behavior of natural ventilation in the experimental measurement, a windy period of time was chosen. However, April and May are months in which the primary mechanisms for the transfer of air into a building occur simultaneously. In this paper we focus on the effect of wind on the NV for a building without a chimney cap and for a building with a chimney cap. The major contribution of the paper is the experimental determination of the performance of natural (stack) ventilation in a residential apartment with a chimney configuration and a window with an inlet gap on the air exchange rate for buildings without and with a chimney cap.

\section{TEST HOUSE}

Long-term investigations were carried out in a residential, multi-family house, located in Gdańsk, northern Poland. The test apartment was inhabited during the measurement campaign. The residents' activity was registered mainly in the morning and in the evening (after 5:00 pm). In the building, there are three stairways, four floors, a full basement with an unused attic and individual one-storey dwellings.

The test apartment was equipped with a natural ventilation system in a configuration with air inlets and chimneys ducts. Air inlets are small appliances mounted in the casement or window frame, which allow for control of the fresh air inflow to the room. They were invented and introduced in the 1960s in Scandinavian countries [4].

The building is made from prefabricated components, and the structural system is mixed. The height of the building from the entry level to the ridge is $14.60 \mathrm{~m}$. A double-sided apartment (including exterior walls oriented in two opposite geographical directions) located on the top floor in the middle of the building was selected. Over the test dwelling, there is an unused and unheated attic. As a thermal barrier for the top floor ceiling, the project adopted the thermal insulation layer separating the apartment from the unused attic, but not the roof surface. Consequently, almost the entire length of the outlet ducts of the ventilation system pass through a space that is not heated and has no contact with the outside air (Fig. 1).

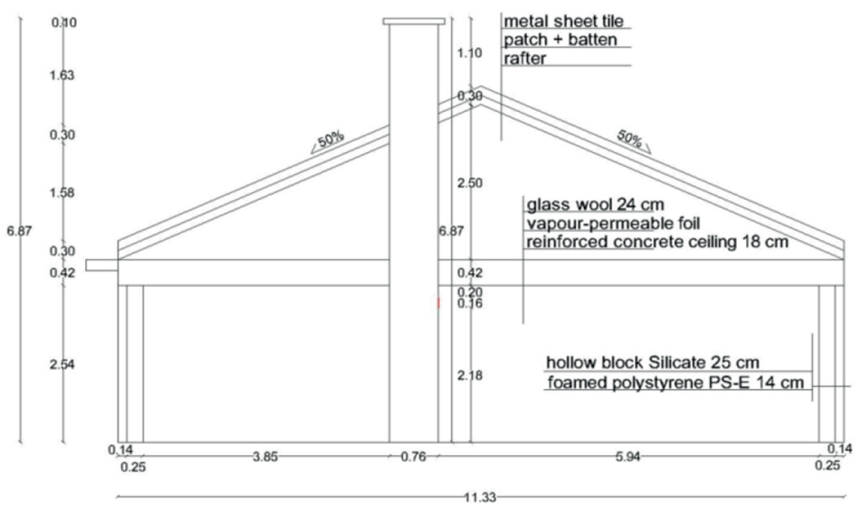

Fig. 1. Vertical cross-section through the attic above test apartment

The construction walls were made from $25 \mathrm{~cm}$ thick silicate blocks and $14 \mathrm{~cm}$ thick insulation, and the ceiling was made of $20 \mathrm{~cm}$ thick Filigran slabs. The roof structure was made from wood components, and the roof surfaces are symmetrical with a $26.5^{\circ}$ slope. The ventilation chimney ducts were made from ceramic blocks $19 / 19 \mathrm{~cm}$ and a cross-section $\varnothing 15 \mathrm{~cm}$ extension on each floor. The transmission heat coefficient $\mathrm{U}$ was $0.25 \mathrm{~W} /\left(\mathrm{m}^{2} \mathrm{~K}\right)$ (external walls), $1.3 \mathrm{~W} /\left(\mathrm{m}^{2} \mathrm{~K}\right)$ (windows) and $0.22 \mathrm{~W} /\left(\mathrm{m}^{2} \mathrm{~K}\right)$ (roof).

\section{MEASUREMENT SETUP AND EQUIPMENT}

The meaning of all symbols and denotations used in the formulae should be explained. To perform measurements, a number of sensors were used: LB-746 sensors to measure the wind velocity and direction, and an LB-801 anemometer with a thermometer function designed to measure the air flow velocity and temperature. All sensors had metrological properties confirmed. The sensors were connected to a data acquisition module. Data collected in the data acquisition module were automatically transferred to the SQL database, located on a PC, on which the measurement data management software LBX 2012 of LAB-EL [18] was installed. The schematic location of the sensors in the apartment is shown in Fig.2.

A description of the measured values and the location of the sensors is presented in Table 1. The sensors were positioned to determine the effect of the wind velocity and direction as well as the outside air temperature on the flow characteristics of the air in the rooms. The arrangements of the sensors were adapted to the expected flow profiles of air in the rooms. This made it possible to identify the velocity and temperature of the air flowing through the characteristic points of internal zones: 
the air flow through the window inlets, a door opening in the inner wall of the living room and the ventilation duct outlet in the bathroom. The outside climate parameters were measured in close proximity to the air ventilation inlet. The location of the sensors made it possible to take into account the air inflow disturbances of the entering air mass on the facade of the building.The continuous measurement of physical values was performed from April till June. The sampling time was 60 seconds. Seven days were taken for analysis of the building without a chimney cap and 7 days for the building with a chimney cap.

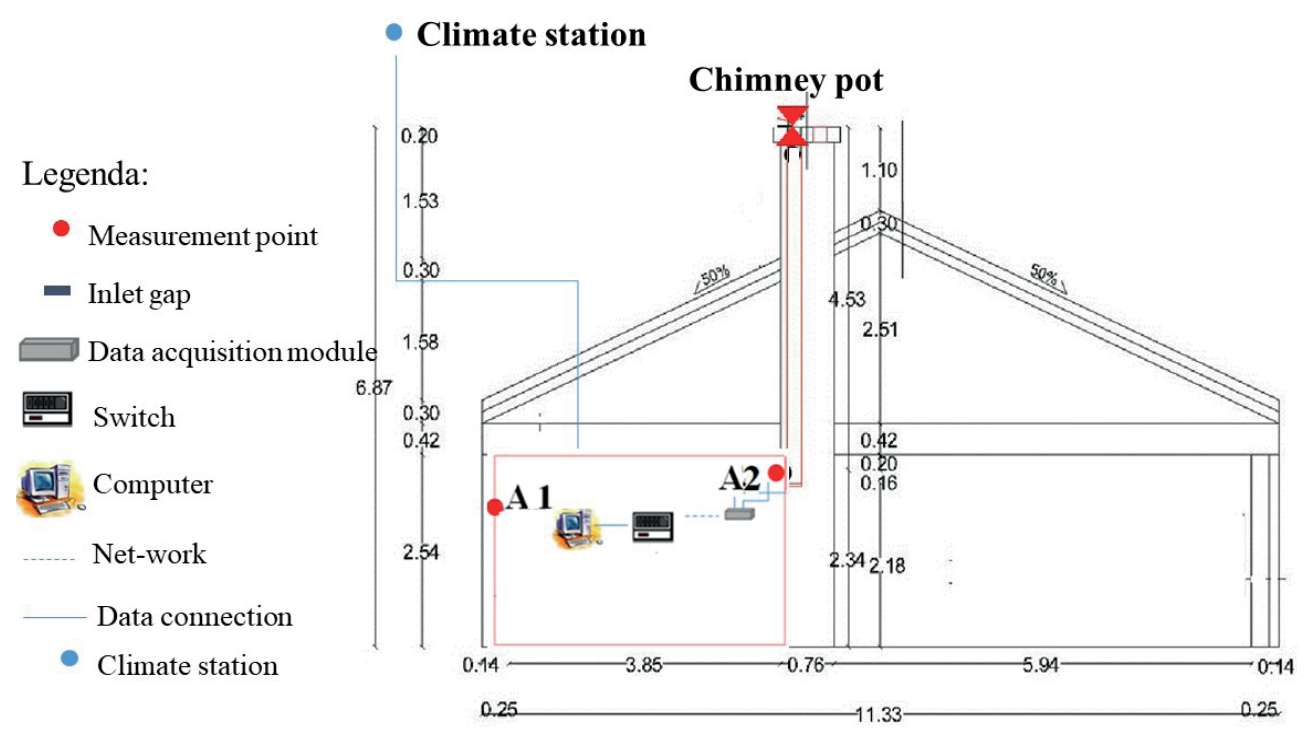

\section{EXTERNAL CLIMATE CONDITIONS}

The measurement campaign was from April till June, when the difference between the indoor and ambient air temperature is higher than $12{ }^{\circ} \mathrm{C}$. Article shows how wind gusts can have a significant influence on the air flow patterns and characteristics. The magnitude of the wind velocity and its direction can rapidly increase the air exchange rate in the air inlet. The characteristics of the wind conditions at the test house location were included in the experiment data. The meteorological station used was located in the middle of an urban area. For the test house, the wind direction profile is presented in Fig.3, which shows the percentage of wind direction at the measurement site according to the measured values. In both cases, similar wind velocity directions were used to compare the results. Due to the location in relation to the parts of world of the building, the biggest impact is that of the wind blowing from the south and west. During the measurement, data was taken when the dominant measured wind direction was the southwest direction SW (75\%) followed by the west W (25\%)

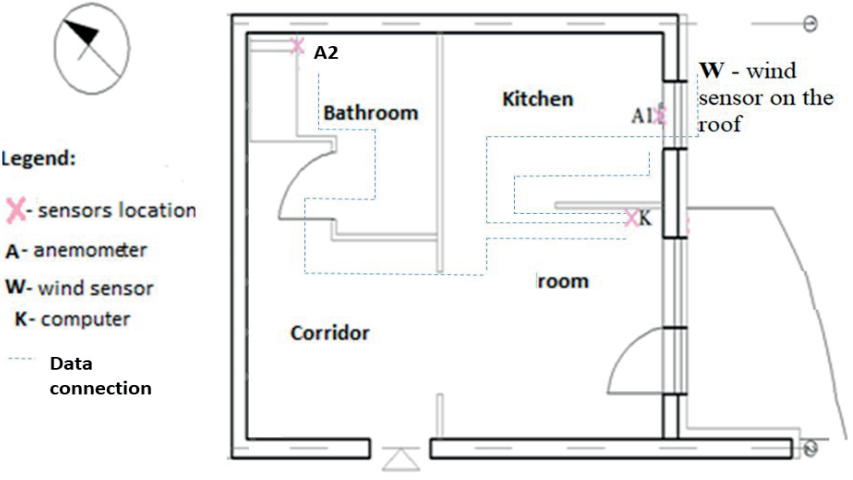

Fig.2. Schematic location of sensors in the apartment

Tab. 1. A description of the measurement sensors

\begin{tabular}{|c|c|c|c|}
\hline Symbol & Sensor name & Measured value & Sensor location \\
\hline \multirow{2}{*}{ W } & Wind sensor & Velocity $[\mathrm{m} / \mathrm{s}]$ & \multirow{2}{*}{$\begin{array}{l}\text { On the railing of the } \\
\text { balcony and parallel } \\
\text { to the facade of the } \\
\text { building. }\end{array}$} \\
\hline & Wind sensor & Direction $\left[^{\circ}\right]$ & \\
\hline \multirow{2}{*}{ A1 } & Anemometer & Velocity $[\mathrm{m} / \mathrm{s}]$ & \multirow{2}{*}{$\begin{array}{l}\text { In the air distribution } \\
\text { opening in the window in } \\
\text { the kitchen. }\end{array}$} \\
\hline & Anemometer & Temperature $\left[{ }^{\circ} \mathrm{C}\right]$ & \\
\hline \multirow{2}{*}{ A2 } & Anemometer & Velocity $[\mathrm{m} / \mathrm{s}]$ & \multirow{2}{*}{$\begin{array}{l}\text { In the ventilation duct } \\
\text { outlet in the bathroom. }\end{array}$} \\
\hline & Anemometer & Temperature $\left[{ }^{\circ} \mathrm{C}\right]$ & \\
\hline
\end{tabular}

for the building without a chimney cap, while for the building with a chimney cap the dominant measured wind direction was again the south-west direction SW (70\%) followed by the west W (30\%).

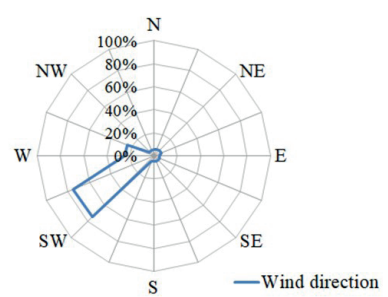

a) building without chimney cap

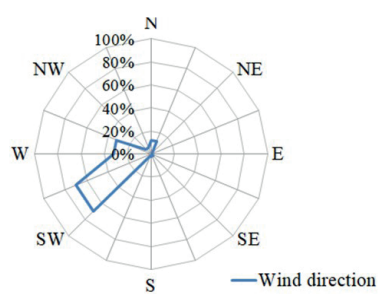

b) building with chimney cap
Fig. 3.The percentage of wind direction at the measurement site according to measured values

In both cases, similar wind velocities were used to compare the results. During the whole period of time, the air velocity in the inlet gap in the window was strongly dependent on the wind velocity. Fig. 4 presents the wind velocity for the buildings without and with a chimney cap. During the experiment the wind velocity was not significant, as its maximum value was at most $4.5 \mathrm{~m} / \mathrm{s}$. 
In order to better capture the influence of natural forces on the velocity of air exchange in the room, a wind velocity above $0.5 \mathrm{~m} / \mathrm{s}$ was assumed for analysis. The average value of the air velocity during the measurements without the chimney cap was $1.49 \mathrm{~m} / \mathrm{s}$, while the average value with a chimney cap was $1.46 \mathrm{~m} / \mathrm{s}$.

The most unpredictable conditions during the entire year for natural ventilation were caused by the wind effect. We already know how strong an impact the wind has on the air change rate in buildings [1]. Besides, we also know that the stack effect is reduced significantly when the impact of wind gusts is significant. Therefore, the wind effect could not be ignored.

Thus, the major contribution of the paper is the experimental determination of the stack effect on the air exchange rate for natural ventilation with an inlet gap subject to the wind effect.

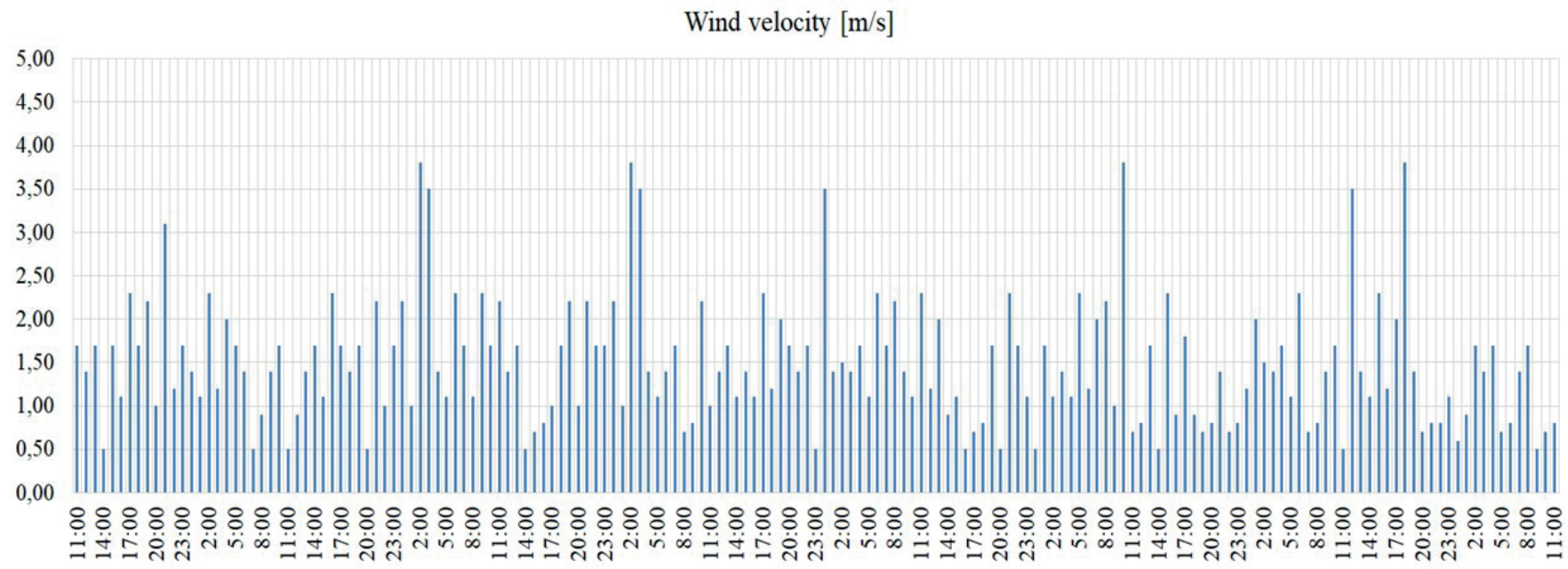

Time

a) building without chimney cap

Wind velocity $[\mathrm{m} / \mathrm{s}]$

5,00

4,50

4,00

3,50

3,00

2,50

2,00

1,50

1,00

0,50

0,00

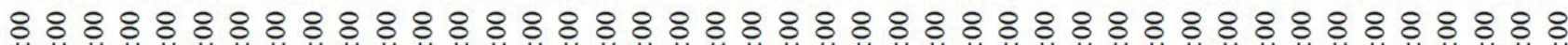

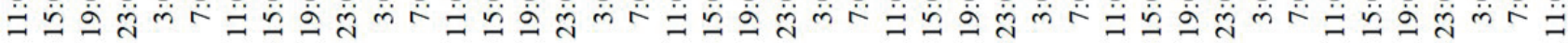
Time

b) building with chimney cap

Fig. 4. The wind velocity for building without chimney cap and for building with chimney cap 


\section{EFFICIENCY OF NATURAL VENTILATION (NV)}

The performance means the air change rate $(\mathrm{ACH})$ and it is the measure of how many times the air within a defined space is replaced $[2,5]$. Air change rates are often used as a principle with broad application that is not intended to be strictly accurate or reliable for every situation in ventilation design.

The air change rate per hour $(\mathrm{ACH})$ is calculated based on the ratio of the total air supply $\left(A_{\text {effinlet }} U_{\text {inlet }}\right)$ (into a zone (i.e. a room or space) in relation to the volume of that zone's room volume $\left(\mathrm{V}_{\mathrm{R}}\right)[3,16]$. The sum of the air supply measured at point A1 constitutes the total air supply into the apartment. The total air supply $\left(A_{\text {effinlet }} U_{\text {inlet }}\right)$ is named $\dot{V}(t)$.It is generally expressed as the air change per hour $\left[\mathrm{h}^{-1}\right]$ or $\mathrm{ACH}$. The $\mathrm{ACH}$ is defined by the ASHRAE as:

$$
A C H(t)=\left(\dot{V}(t) * 3600 / V_{R}\right.
$$

where:

$\mathrm{ACH}(\mathrm{t})$ - the ventilation rate or air change rate, $\mathrm{h}-1$ $\dot{V}(\mathrm{t})$ - the total air supply into a room, $\mathrm{m}^{3} / \mathrm{h}$

$\mathrm{VR}$ - the room's volume, $\mathrm{m}^{3}$

The exchange processes that take place during the measurement period are assumed to be temporally invariant. The air supply rate $\dot{V}(\mathrm{t})$ and thus the air change rate $\mathrm{ACH}(\mathrm{t})$ are constant. $\dot{V}(\mathrm{t})$ and $\mathrm{ACH}(\mathrm{t})$ can be replaced by $\dot{V}$ and $\mathrm{ACH}$ $[13,15]$.For the air change rate, which is designed to calculate the performance of ventilation, the following simplifying assumptions have been made:

- the air is considered to be completely mixed throughout the measurements. Inside the room there are no concentration gradients, i.e. the concentration of air at a given time is the same for the whole room,

- the rooms presented in Fig.1 are considered a single zone system.

\section{DISCUSSION OF RESULTS}

In the cold climate conditions of northern Poland, ventilation works in a winter regime from November to March, with January the coldest month. The average temperature is about $-4^{\circ} \mathrm{C}$ but it can fall as low as $-35^{\circ} \mathrm{C}$. On the other hand, in the summer months of June, July and August, the average temperature is about $18^{\circ} \mathrm{C}$ and the maximum summer temperature is $40^{\circ} \mathrm{C}$. All other time periods can be called transient climate conditions (TCC), which are characterized in this article by a day-time difference between the indoor and ambient temperature in the range of about $\left(20^{\circ} \mathrm{C},-2^{\circ} \mathrm{C}\right)$. These are the most unfavorable conditions during the entire year. This is due to the stack effect being reduced significantly, while the impact of wind gusts is very random and dependent upon the ventilation configuration. However, the time period of transient climate conditions is very advantageous for field investigations of the quality of natural ventilation.

In this study, the test apartment was equipped with one air inlet gap located in the kitchen. According to the national regulations and standards [16], the active flow area of a fully open air-inlet should be designed to enable airflow in the range from 20 to $50 \mathrm{~m}^{3} / \mathrm{h}$ for a pressure difference of $10 \mathrm{~Pa}$ on both sides of the opening. In the test apartment, the inlet gap was located only in the kitchen and was in contact with the ambient air. When fully opened, it should ensure an air exchange rate of $0.8 \mathrm{1} / \mathrm{h}$. The chimney duct of $14 \mathrm{x} 14 \mathrm{~cm}^{2}$ (min. $0.016 \mathrm{~m}^{2}$ ) was located in the bathroom. The active area of the air inlet to the chimney duct was $0.008 \mathrm{~m}^{2}$. During measurements the test apartment was occupied by two adults at the same times of the day: before work (6:00-7:00 am) and after work (6:00-10:00 pm).

For better knowledge of the influence of wind on the ACH in the building, the study includes a windy period with a wind velocity higher than $0.5 \mathrm{~m} / \mathrm{s}$. The ventilation performance was investigated as the air change rate per the apartment's total volume during $1 \mathrm{~h}(\mathrm{ACH})$. The results were compared with the requirements of the industry standard [17] (natural ventilation in the test apartment should exchange $50 \mathrm{~m}^{3} / \mathrm{h}$ of air during the day-time).

Fig. 5 shows the wind effect for a velocity measurement at point A1. In order to better understand the influence of the chimney cap on the improvement of natural ventilation, the direction of the wind was selected from the side of the building in which the window gap was located. The results of measurements of velocity (Fig. 5) in the inlet in the window showed a distinct relation between the external wind velocity and the airflow direction in the air inlet. The air velocity at the inlet is directly proportional to the wind speed.

Fig. 6 shows the wind effect on the flow rate in the apartment. For a wind velocity higher than $0.5 \mathrm{~m} / \mathrm{s}$, the day-time flow rate was fulfilled for $48 \%$ of the time without a chimney cap, while for the chimney with a cap the day-time flow rate was fulfilled for $60 \%$ of the time.

Fig. 6 shows a large time-variation of the $\mathrm{ACH}$ during a windy period typical of the cold climate in Poland. Considering this time-variation, the air change rate in the experiment varied between a minimum of $\mathrm{ACH} \approx 0.23 \mathrm{~h}^{-1}$ and a maximum of $\mathrm{ACH} \approx 2.59 \mathrm{~h}^{-1}$ for the measurement without a chimney cap, and between a minimum of $\mathrm{ACH} \approx 0.22 \mathrm{~h}^{-1}$ and a maximum of $\mathrm{ACH} \approx 3.84 \mathrm{~h}^{-1}$ for the measurement with a chimney cap. The average value of the air change rate during the measurements without a chimney cap was $0.88 \mathrm{~h}^{-1}$, while the average value of the $\mathrm{ACH}$ during the measurements with a chimney cap was $1.04 \mathrm{~h}^{-1}$. 


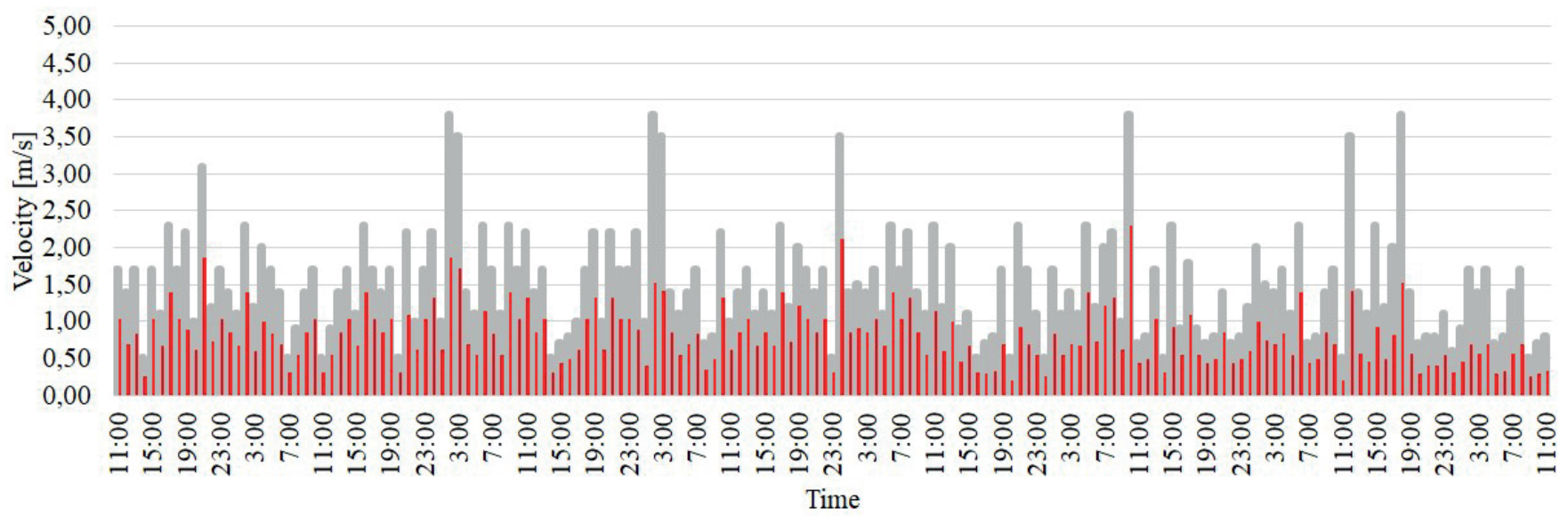

Wind velocity $[\mathrm{m} / \mathrm{s}] \quad$ Velocity in inlet gap (A 1$)[\mathrm{m} / \mathrm{s}]$

a) building without chimney cap

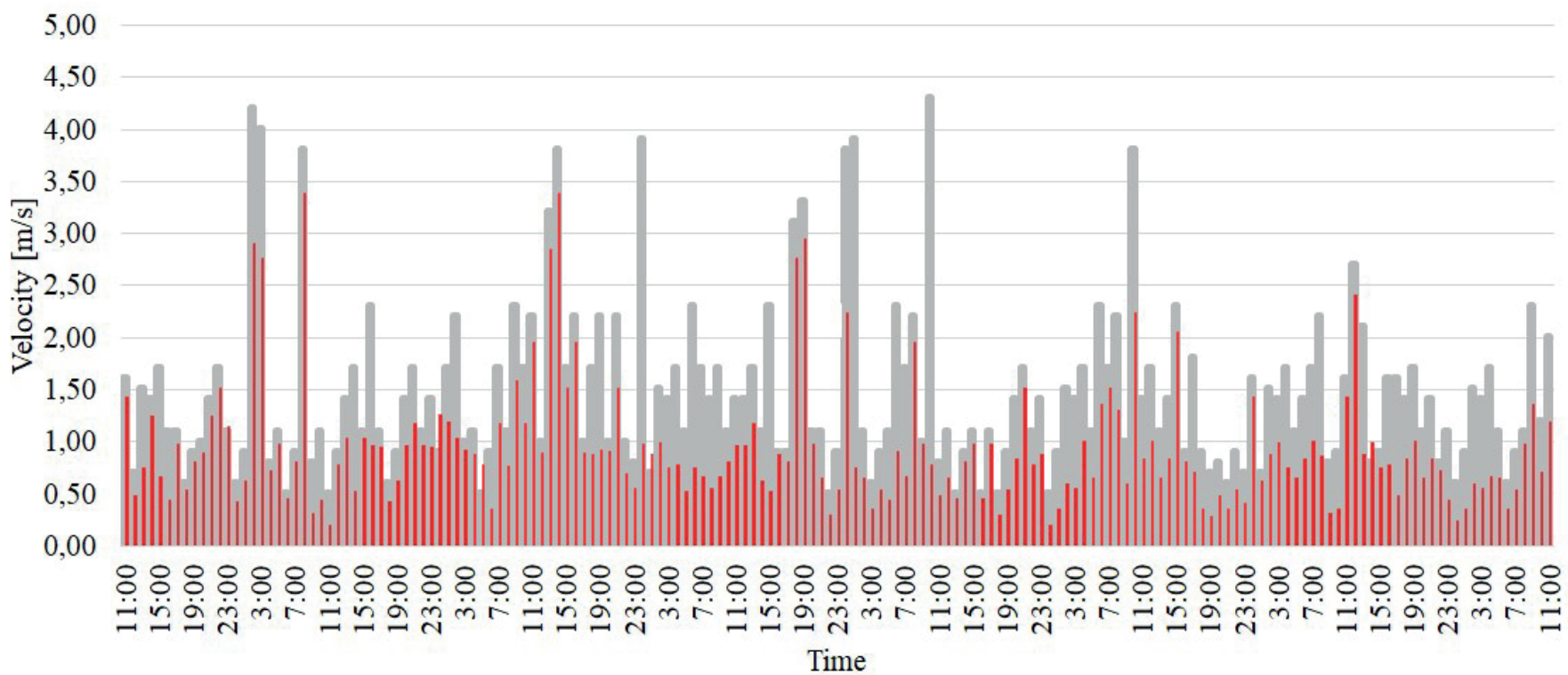

Wind velocity $[\mathrm{m} / \mathrm{s}]$ Velocity in inlet gap (A 1) $[\mathrm{m} / \mathrm{s}]$

b) building with chimney cap

Fig.5. Wind effect for a velocity measurement in point $A 1$ 


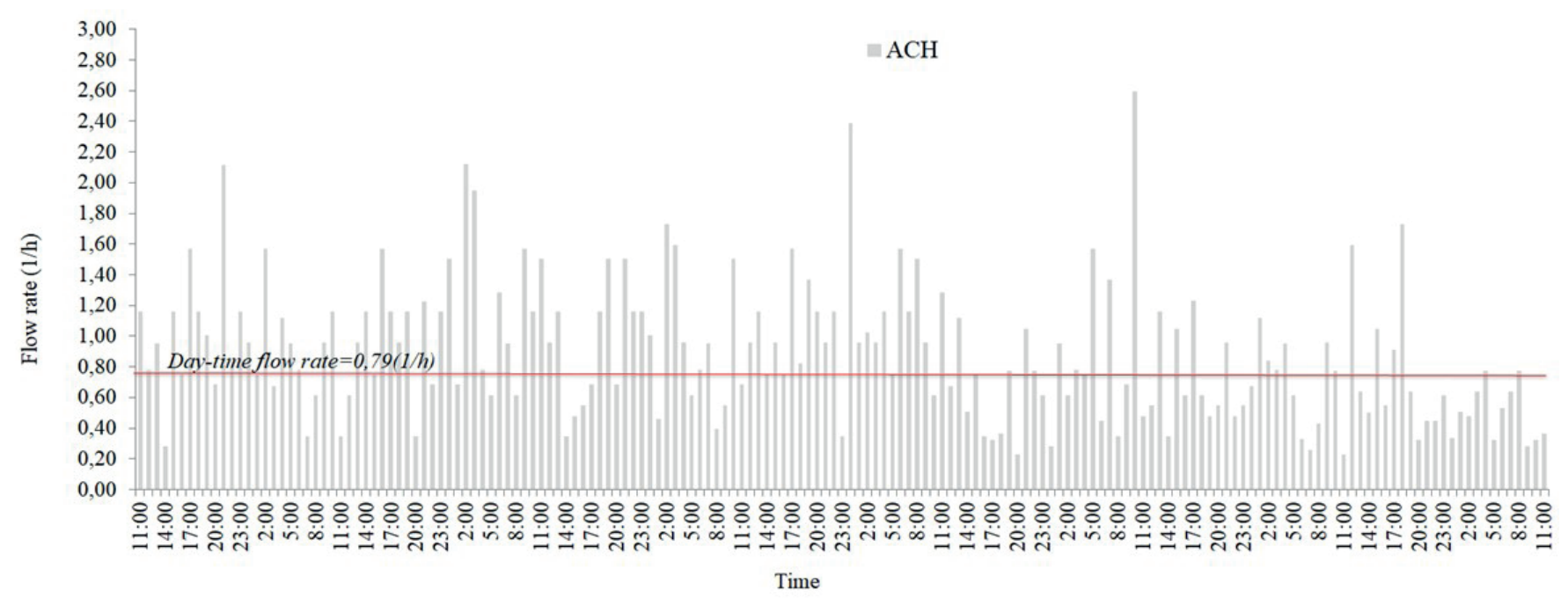

a) building without chimney cap

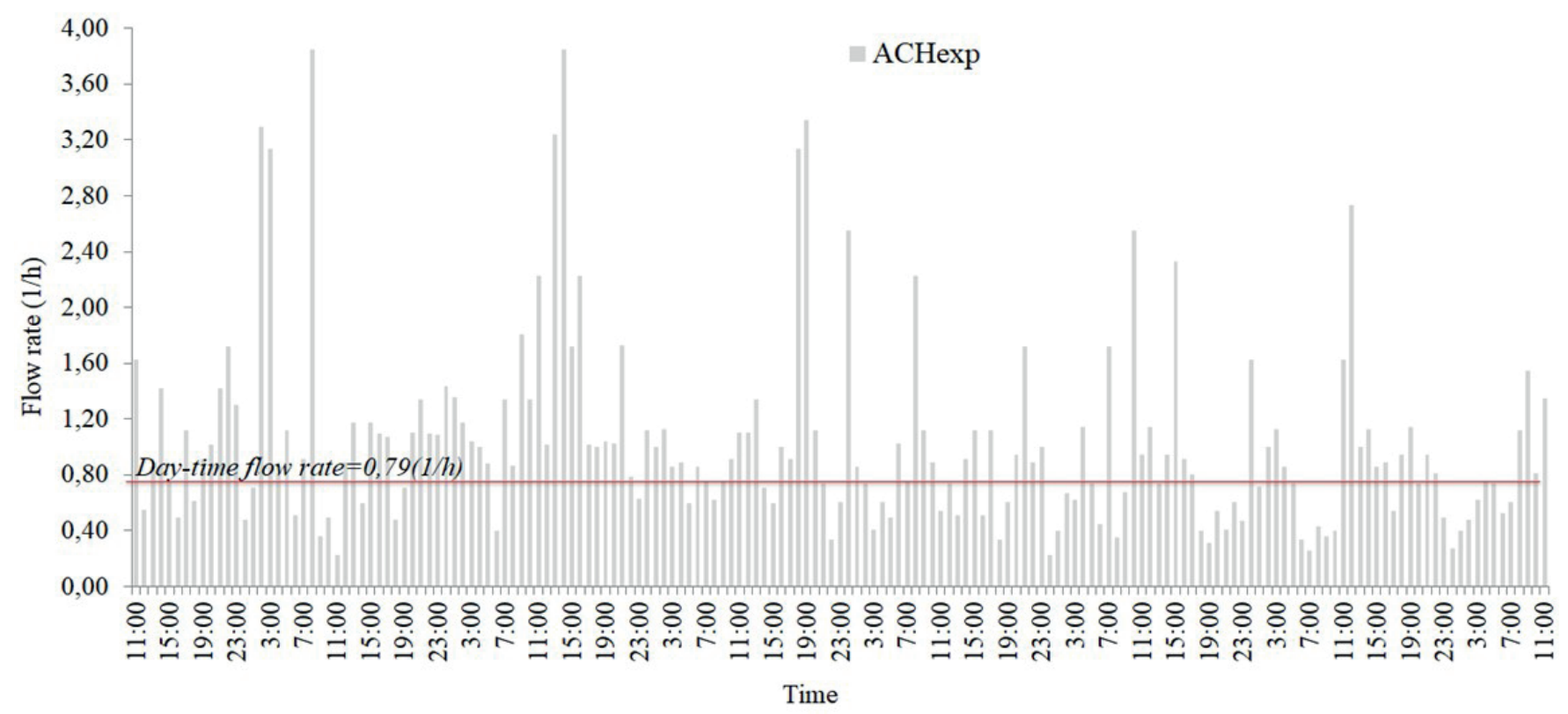

b) building with chimney cap

Fig.6. Ventilation performance in the test apartment with respect to air change rates $(A C H)$ was selected

\section{CONCLUSIONS}

Field investigations on the prediction of the air flow rate in an apartment with natural (stack) ventilation with an inlet gap in a window, with and without a chimney cap, were performed. The measurements were carried out in a test apartment within a detached family house located in a cold climate. The measurement campaign was conducted in transient climate conditions.
The $\mathrm{ACH}$ was investigated under steady climate conditions in a windy period. The main influence on the $\mathrm{ACH}$ in the apartment was the wind velocity normal to the inlet. The results of measurements of velocity at the inlet in the window showed a distinct relation between the external wind velocity and the airflow direction in the air inlet. The air velocity at the inlet is directly proportional to the wind speed. The minimum value which fulfilled the day-time flow rate requirement was a wind velocity in the inlet (A1) equal to $0.7 \mathrm{~m} / \mathrm{s}$. 
The experiment shows the large time-variation of the $\mathrm{ACH}$ during a windy period typical of the cold climate in Poland.

The maximum value of the $\mathrm{ACH}$ with a chimney cap was $3.84 \mathrm{l} / \mathrm{h}$, which was $48 \%$ higher than the maximum $\mathrm{ACH}$ for a standard chimney without a chimney cap.

The use of the chimney cap improves the efficiency of natural ventilation by $15.5 \%$.It is surprising, however, that, despite the chimney cap, the windy period and the measurements at a time when the wind direction was directed towards the window with the inlet gap for as much as $40 \%$ of the time, the day-time standard flow rate was not met.

\section{REFERENCES}

1. Awbi H. (1991):Ventilation of buildings, Chapman \& Hall.

2. Awbi H., Gan G. (1992): Simulation of solar induced ventilation, Second World Renewable Energy Congress, vol. 4, Solar and Low Energy Architecture, September 1992, Pergamon Press, Oxford.

3. Axley J. (1998): Introduction to the design of natural ventilation system loopequation, Proc. 19th AIVC Conf. Ventilation Technologies Urban Areas, 47-56.

4. Bülow-Hübe H. (2001): Energy-Efficient Window Systems. Doctoral Dissertation. ISSN 1103-4467. Lund University, Lund Institute of Technology, Lund.

5. Cao G., Awbi H., Yan R., Fan Y., Siren K., Kosonen R., Zhang J. (2014): A review of the performance of different ventilation and airflow distribution systems in buildings. Buildings and Environment, 73, 171-186.

6. Clarke D. (2001): A breath offresh air. Hospital Development, 32(11), 13-17.

7. FitzgeraldS.D., Woods A.W.(2008): The influence of stacks on flow patterns and stratification associated with natural ventilation.Energy and Buildings, 43, 1719-1733.

8. Gładyszewska-Fiedoruk K., Gajewski A. (2012): Effect of wind on stack ventilation performance. Energy and Buildings, 51, 242-247.

9. Jarząbska-Antczak R., Niedostatkiewicz M. (2017): Design and diagnostics of gravitational ventilation. Selected problems.

10. Polskie Centrum Budownictwa Difin i Muller sp. z o.o., 1-80, Warszawa.

11. Krishan A. (2001): Climate responsive architecture: a design handbook for energy efficient buildings, Tata McGraw-Hill, New York.
12. LBNL (2007):Energy Plus Engineering Reference, November 6, 2007, pp. 384 and 381.

13. Nazaroff W. W. (2008): Inhalation intake fraction of pollutants from episodic indoor emissions. Building and Environment, 43(3), 269-277.

14. Novoselac A., Srebric J. (2003): Comparison of air exchange efficiency and contaminant removal effectiveness as IAQ indices. ASHRAE Trans., 109, 339-349.

15. Okisalo J., Kurnitski J., Korpi M., Kalamees T., Vinha J.(2009): Building leakage, infiltration, and energy performance analyses for Finnish detached houses. Building and Environment, 44, 377-387.

16. Roos A. (1998): The air exchange efficiency of the desk displacement ventilation concept-Theory, measurements and simulations, Proc. Roomvent'98, vol.1, pp.249-256, Stockholm, Sweden.

17. Sandberg M. (1981): What is ventilation efficiency? Building and Environment, 16, 123-135.

18. PN-83/B-03430 (including revision A3:2000). Ventilation in collective dwelling places and public buildings - requirements, (in Polish).

19. LAB-EL Elektronika Laboratoryjna s.j. Available from www.label.pl.

\section{CONTACT WITH THE AUTHORS}

\author{
Romana Antczak-Jarząbska \\ e-mail:romana.antczak@pg.edu.pl \\ Maciej Niedostatkiewicz \\ e-mail:mniedost@pg.edu.pl
}

Gdańsk University of Technology

11/12 Gabriela Narutowicza Street 80-233 Gdańsk

Poland 